\title{
Short communication: Space allocation in intensive Mediterranean buffalo production influences the profile of functional biomolecules in milk and dairy products
}

\author{
Angela Salzano, ${ }^{1 *}$ Francesca Licitra, ${ }^{2}$ Nunzia D'Onofrio, ${ }^{3}$ Maria Luisa Balestrieri, ${ }^{3}$ Antonio Limone, ${ }^{4}$ \\ Giuseppe Campanile, ${ }^{1 *}$ Michael J. D'Occhio, ${ }^{5}$ and Gianluca Neglia ${ }^{1}$ \\ ${ }^{1}$ Department of Veterinary Medicine and Animal Productions, University of Naples Federico II, 80137 Naples, Italy \\ ${ }^{2}$ Veterinary practitioner, 97100 Ragusa, Italy \\ ${ }^{3}$ Department of Precision Medicine, University of Campania Luigi Vanvitelli, 80138 Naples, Italy \\ ${ }^{4}$ Istituto Zooprofilattico Sperimentale del Mezzogiorno (IZSM), Portici, 80055 Naples, Italy \\ ${ }^{5}$ School of Life and Environmental Sciences, Faculty of Science, University of Sydney, Camden, New South Wales 2006, Australia
}

\section{ABSTRACT}

The aim of the present study was to determine if space allocation influenced the concentration of biomolecules in buffalo milk and dairy products. Intensively housed buffaloes $(\mathrm{n}=96)$ were randomly assigned to 2 groups according to days in milk, parity, and milk yield: group S10 had a space allocation of $10 \mathrm{~m}^{2}$ per buffalo and group S15 had a space allocation of $15 \mathrm{~m}^{2}$ per buffalo. Individual milk yield was recorded daily. Twice a month, a bulk milk sample was collected for each group, as well as whey, ricotta, and mozzarella cheese, to assess cheese yield and to conduct HPLC-electrospray ionizationtandem mass spectrometry, milk antioxidant activity, and cell viability analyses. We tested milk extracts from the 2 groups in vitro to evaluate their efficacy in counteracting endothelial oxidative damage induced by high glucose. We evaluated reproductive function in 28 buffaloes from each group using the Ovsynchtimed artificial insemination program. We observed no differences in milk quantity or quality in terms of fat, protein, or lactose, and reproductive function did not differ between the 2 groups. Compared with group S10, group S15 had higher concentrations of carnitine (56.7 \pm 1.1 vs. $39.8 \pm 0.7 \mathrm{mg} / \mathrm{L}$ in milk and $40.9 \pm 0.8$ vs. $31.7 \pm 0.7 \mathrm{mg} / \mathrm{L}$ in whey), acetyl-L-carnitine (51.9 \pm 0.3 vs. $39.7 \pm 0.7 \mathrm{mg} / \mathrm{L}$ in milk and $41.1 \pm 1.7$ vs. $28.7 \pm 2.6 \mathrm{mg} / \mathrm{L}$ in whey), propionyl-L-carnitine (34.8 \pm 1.0 vs. $21.0 \pm 0.9 \mathrm{mg} / \mathrm{L}$ in milk and $26.9 \pm 0.8$ vs. $17.6 \pm 1.2 \mathrm{mg} / \mathrm{L}$ in whey), glycine betaine $(23.1 \pm 1.9$ vs. $13.5 \pm 1.6 \mathrm{mg} / \mathrm{L}$ in milk and $10.7 \pm 0.4$ vs. $7.9 \pm$ $0.5 \mathrm{mg} / \mathrm{L}$ in whey), and $\delta$-valerobetaine $(24.2 \pm 0.5$

Received March 20, 2019.

Accepted April 25, 2019.

*Corresponding author: giucampa@unina.it vs. $16.7 \pm 0.5 \mathrm{mg} / \mathrm{L}$ in milk and $22.0 \pm 0.9$ vs. $15.5 \pm$ $0.7 \mathrm{mg} / \mathrm{L}$ in whey). Group S15 also had higher total antioxidant activity than group S10 $(56.7 \pm 1.9$ vs. 46.4 $\pm 1.13 \mathrm{~m} M$ Trolox equivalents). Co-incubation of highglucose-treated endothelial cells with milk extracts from group S15 improved cell viability compared with cells treated with high glucose only; it also reduced intracellular lipid peroxidation $(144.3 \pm 0.4$ vs. $177.5 \pm$ $1.9 \%)$, reactive oxygen species $(141.3 \pm 0.9$ vs. $189.3 \pm$ 4.7 optical density units), and cytokine release (tumor necrosis factor- $\alpha$, IL-1 $\beta$, IL-6). Greater space allocation was associated with higher levels of biomolecules in buffalo milk. This could have been the result of improved welfare in buffaloes that were allocated more space.

Key words: buffalo welfare, functional biomolecules, cytokine, milk, dairy products

\section{Short Communication}

Milk from the Italian Mediterranean water buffalo (Bubalus bubalis) is used to produce high-value products, including mozzarella cheese (Addeo et al., 2007). The global demand for mozzarella has led to the expansion of intensive buffalo production in Italy. Intensification has allowed better control of the buffaloes' diet and husbandry, which has improved the efficiency and the amount of milk produced by individual buffalo cows (De Rosa et al., 2005). Animal welfare has become an important consideration in contemporary intensive livestock production systems, recognizing the fundamental role of welfare in animal health, productivity, and product quality and safety (Broom, 2010). One study showed that the amount of milk produced by buffalo cows did not differ for animals allocated 10 or 22 $\mathrm{m}^{2}$ of space per animal (Salzano et al., 2017). However, the quality of buffalo milk is arguably more important than the quantity. Space allocation may influence the levels of important bioactive molecules that have high 
nutritional value and health-promoting properties. Particularly important components of buffalo milk are L-carnitine (Car) and short-chain acylcarnitines (Servillo et al., 2018a). Levels of acetyl-L-carnitine $\left(\mathrm{C}_{2} \mathrm{Car}\right)$, propionyl-L-carnitine $\quad\left(\mathrm{C}_{3} \mathrm{Car}\right)$, butyryl-L-carnitine $\left(\mathrm{nC}_{4} \mathrm{Car}\right)$, and isobutyryl-L-carnitine $\left(\mathrm{iC}_{4} \mathrm{Car}\right)$ are related to anaerobic fermentation in the rumen, which produces volatile fatty acids and isoacids (Rychlik et al., 2002). The recently identified milk $\delta$-valerobetaine ( $N, N, N$,-trimethyl-5-aminovaleric acid) is synthesized by rumen microbiota, most likely during the anaerobic oxidative deamination of $N^{e}$-trimethyllysine and glycine (Stickland reaction; Servillo et al., 2018b). The occurrence of $\delta$-valerobetaine in ruminant milk, along with $\gamma$-butyrobetaine (the immediate biosynthetic precursor of Car) suggests that buffalo milk has broader healthpromoting properties. Indeed, $\delta$-valerobetaine has in vitro antioxidant and anti-inflammatory activities against high-glucose-induced endothelial damage, and it decreases $\beta$-oxidation of fatty acids in mouse cardiomyocytes (Kärkkäinen et al., 2018a; D'Onofrio et al., 2019). In humans, the beneficial effects of a diet rich in whole grains correlates with increased plasma levels of $\delta$-valerobetaine and improved insulin resistance and secretion (Kärkkäinen et al., 2018b). It is important that production systems do not reduce the biomolecules in buffalo milk that confer high nutritional value and health-promoting properties. The aim of the present study was to examine the effect of space allocation on carnitine and its precursors in buffalo milk. The hypothesis tested was that greater space allocation would be beneficial for the biomolecule profile in buffalo milk.

The Ethical Animal Care and Use Committee of the Federico II University of Naples approved the experimental design and animal treatments. The study was undertaken from October 2017 to January 2018 (100 d) in a commercial buffalo dairy in southern Italy. The animals were maintained in pens with a concrete floor and milked twice per day. Buffaloes were fed the same TMR during the study (Table 1). Feed intake was determined from feed that remained unconsumed before the next feeding. The amount and composition of remaining feed was used to calculate DMI and diet composition. Individual feedstuff and remaining feed were sampled approximately once per week and analyzed according to AOAC (1980). We calculated energy values (milk forage units $=1,700 \mathrm{kcal}$ ) using equations provided by the INRA (1988) and the Nutrient Requirements of Dairy Cattle (NRC, 2001). Individual feed intake was estimated as suggested by Campanile et al. (1998).

Buffaloes $(\mathrm{n}=96)$ were randomly assigned to 1 of 2 groups according to DIM, parity, and milk yield: group S10 had a space allocation of $10 \mathrm{~m}^{2}$ per buffalo, and group S15 had a space allocation of $15 \mathrm{~m}^{2}$ per buffalo. The 2 groups were maintained in similar pens with a concrete floor. After an adaptation period of $15 \mathrm{~d}$, we collected a bulk milk sample twice a month for analysis and to assess cheese yield. On the same days, we collected and analyzed samples of milk, whey, ricotta, and mozzarella cheese from each group. Throughout the experimental period, we recorded milk yield per individual cow each day, and performed milk sampling 15 d apart for chemical analysis by infrared spectroscopy (MilkoScan, FTplus 6000; Foss-Electric, Hillerød, Denmark). At the same time, we assessed the BCS of each buffalo on a scale of 1 to 9 (Wagner et al., 1988). Eighty days after the start of the trial, 28 buffaloes in each group underwent synchronization of ovulation and artificial insemination using the Ovsynch-timed AI program (Neglia et al., 2003, 2016). Pregnancies were confirmed by ultrasonography on d 45 after insemination.

Extracts of buffalo milk, whey, ricotta, and mozzarella cheese were prepared and analyzed by HPLC electrospray ionization-tandem MS for Car, $\mathrm{C}_{2} \mathrm{Car}$, $\mathrm{C}_{3} \mathrm{Car}, \mathrm{nC}_{4} \mathrm{Car}$, glycine betaine, $\gamma$-butyrobetaine, and $\delta$-valerobetaine, as described by Servillo et al. (2018a,b). We determined milk antioxidant activity by measuring total antioxidant capacity, free radical scavenging ac-

Table 1. Feed (kg of feed) and chemical composition (\% of DM) of the diet fed to buffaloes in both space allocation groups

\begin{tabular}{lc}
\hline Item & Amount \\
\hline Component (kg of feed) & 23 \\
Corn silage & 1 \\
Straw & 3.5 \\
Hay (alfalfa second cut) & 5.8 \\
Concentrate & 0.3 \\
Hydrogenated fats & 0.12 \\
1:3 Salt & 0.03 \\
Calcium carbonate & 0.2 \\
Vitamin/mineral supplement ${ }^{1}$ & \\
Composition (\% of DM) & 14.60 \\
CP & 19.80 \\
Crude fiber & 5.20 \\
Ether extract (fat) & 19.90 \\
Starch & 10.24 \\
Ash & 40 \\
NDF & 24 \\
ADF & 0.88 \\
Calcium & 0.44 \\
Phosphorus & 0.93 \\
Milk forage units & \\
\hline 1Declared mineral and vitamin content per kg: vitamin A $4,000,000$ \\
IU; vitamin D 100,000 IU; vitamin E 1,500 mg; vitamin B 1,000 mg; \\
vitamin B 500 mg; vitamin B B $_{2}$ mg; biotin 1,000 mg; niacin 10,000 \\
mg; pantothenic acid 1,000 mg; choline chloride 50,000 mg; Ca 180 g; \\
Co 210 mg; Fe 9,000 mg; Mn 10,000 mg; Cu 900 mg; I 1,000 mg; Zn \\
16,000 mg; Se 10 mg.
\end{tabular}


tivity, and reducing power, as described by D'Onofrio et al. (2019).

Endothelial cells (CCL 209; ATCC, Manassas, VA) were grown at $37^{\circ} \mathrm{C}$ in a humidified atmosphere $(95 \%$ air, 5\% $\left.\mathrm{CO}_{2}\right)$ in minimum essential medium (11095080, Gibco; Thermo Fisher Scientific, Waltham, MA) supplemented with $20 \%$ heat-inactivated fetal bovine serum, penicillin $(100 \mathrm{U} / \mathrm{mL})$, streptomycin $(0.1 \mathrm{mg} /$ $\mathrm{mL}$ ), and NEAA (1\%) solution. Cells were treated with buffalo milk extract $(10 \mu \mathrm{L})$, added to culture medium and then treated with normal glucose $(5.5 \mathrm{mM})$ or high glucose $(30 \mathrm{~m} M)$ for $48 \mathrm{~h}$ (D'Onofrio et al., 2019). Cell viability was determined by XTT assay (X4626; Sigma Aldrich, St. Louis, MO; D'Onofrio et al., 2019). We determined intracellular reactive oxygen species levels, lipid oxidative degradation, and cytokine release [tu-

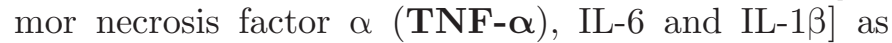
previously described (D'Onofrio et al., 2019).

Data for milk production, quality, and composition (in terms of bioactive peptides, were analyzed using repeated-measures ANOVA; findings are presented as mean \pm standard error. Data from in vitro experiments are also presented as mean \pm standard error. We performed statistical analysis using SPSS for Windows 17.0 (SPSS Inc., Chicago, IL). A statistically significant difference was accepted at $P<0.05$.

Dry matter intake throughout the experimental period was similar between the 2 groups $(16.4 \pm 0.1$ vs. $16.5 \pm 0.1 \mathrm{~kg}$ in groups S15 and S10, respectively). Total milk yield per buffalo was higher in group S15 throughout the experimental period $(764.9 \pm 1.5$ vs. $743.4 \pm 1.7 \mathrm{~kg}$ for group S10, $P<0.01)$. During the first $7 \mathrm{wk}$, we recorded similar production between the 2 groups $(8.4 \pm 0.1 \mathrm{~kg} / \mathrm{d}$ vs. $8.4 \pm 0.2 \mathrm{~kg} / \mathrm{d})$, but observed significant differences from wk 8 onward $(6.7 \pm$ $0.3 \mathrm{~kg} / \mathrm{d}$ vs. $6.4 \pm 0.3 \mathrm{~kg} / \mathrm{d}$ for groups S15 and S10, respectively, $P<0.01)$. We recorded no differences between the 2 groups in terms of milk gross composition or cheese yield. During the trial, BCS was similar between the 2 groups. Regarding reproductive efficiency, 2 buffaloes for each group were not in estrus at the time of artificial insemination and were excluded from the trial. We observed no differences in pregnancy rate between the 2 groups (69.2 vs. $73.1 \%$ in groups S15 and S10, respectively).

Compared with group S10, milk and whey from group S15 contained higher levels of Car, $\mathrm{C}_{2} \mathrm{Car}, \mathrm{C}_{3} \mathrm{Car}$, $\delta$-valerobetaine, and glycine betaine $(P<0.01$; Table 2 ). Among the dairy products analyzed, we observed no differences in the mozzarella and ricotta cheese (Table $2)$. Milk total antioxidant activity, DPPH (2,2-diphenyl-1-picrylhydrazyl) activity and ferric reducing power were higher in group S15 than in group S10 [56.7 \pm 1.9 vs. $46.4 \pm 1.1 \mathrm{mM} ; 159 \pm 3.1$ vs. $121 \pm 5.9 \%$ of control;

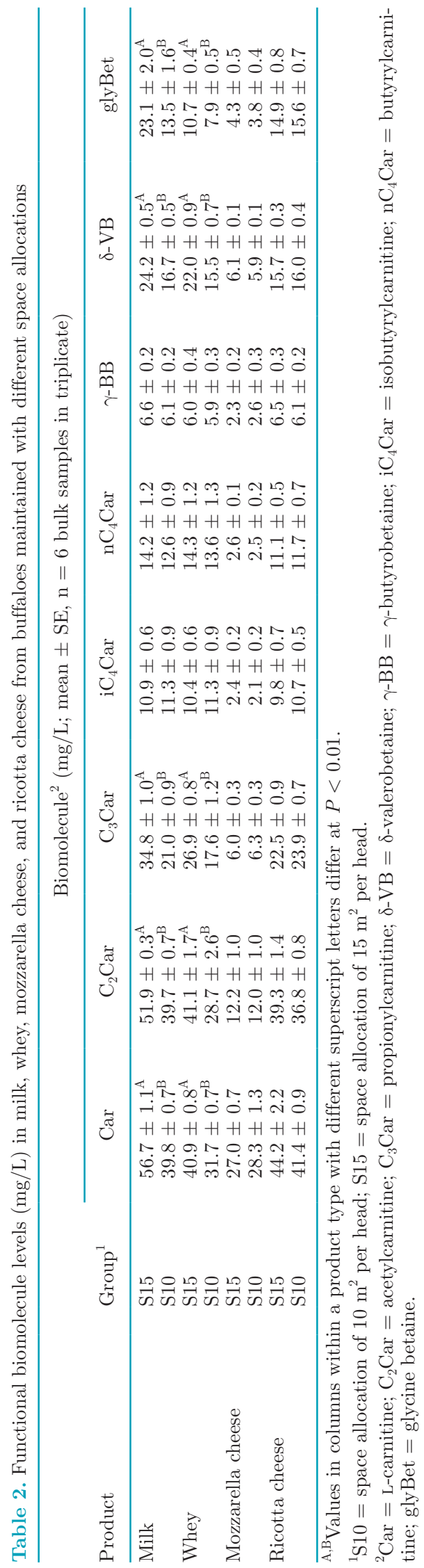

Journal of Dairy Science Vol. 102 No. 9, 2019 

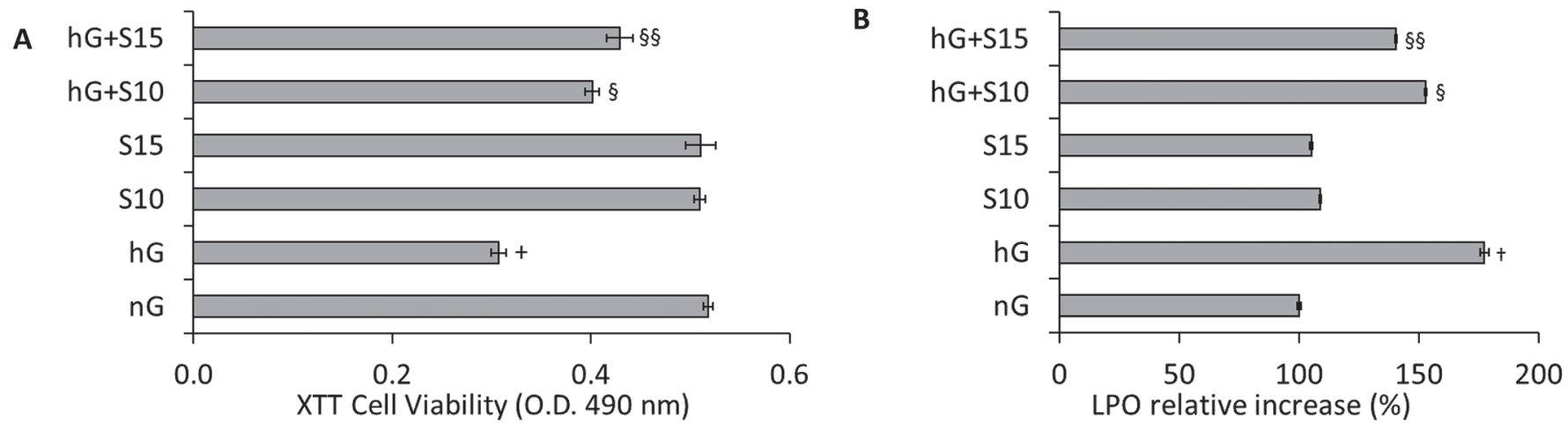

C
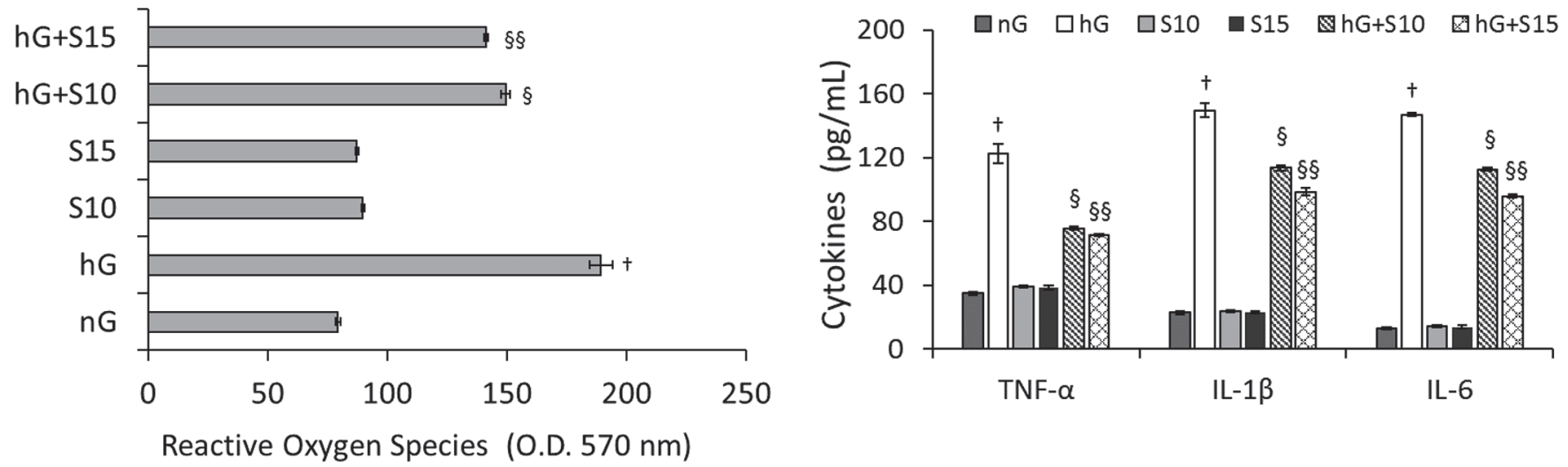

Figure 1. Cytoprotective effect of milk extracts from buffalo housed with space allocations of 10 (group S10) or $15 \mathrm{~m}^{2}$ (group S15) per animal. Measured after $48 \mathrm{~h}$ of treatment with normal glucose $(\mathrm{nG})$, high glucose $(\mathrm{hG})$, or S15 or S10 milk extract, alone or in combination with hG. (A) Endothelial cell viability (XTT assay; Sigma Aldrich, St. Louis, MO); (B) lipid peroxidation (LPO); (C) intracellular reactive oxygen species; and (D) cytokine levels. Results are the mean $\pm \mathrm{SE}$ of 6 independent experiments; $\dagger P<0.001$ vs. nG, $\S P<0.01$ vs. hG; $\S \S P<0.001$ vs. hG. OD = optical density; TNF- $\alpha=$ tumor necrosis factor- $\alpha$.

$12.9 \pm 0.8$ vs. $9.0 \pm 0.9$ optical density units $(\mathbf{O D})$ at $700 \mathrm{~nm} ; P<0.05]$.

When S15 and S10 milk extracts were tested in vitro to evaluate their efficacy in counteracting the endothelial oxidative damage induced by high glucose, results showed an improvement in cell viability during co-incubation with milk extract from group S15 ( $P$ $<0.001$; Figure 1A). This effect was paralleled by a reduction in intracellular lipid peroxidation (144.3 \pm 0.41 vs. $177.5 \pm 1.9 \% ; P<0.001$; Figure $1 \mathrm{~B}$ ), reactive oxygen species $(141.3 \pm 0.88$ vs. $189.3 \pm 4.69 \mathrm{OD} ; P<$

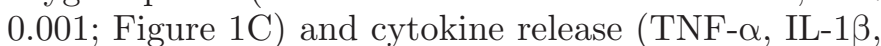
IL-6); the efficacy of the milk extract from group S15 $(P<0.001$ vs. high glucose $)$ was higher than that of group S10 $(P<0.01$ vs. high glucose).

Concentrations of carnitine, short-chain acylcarnitines, and $\delta$-valerobetaine in fresh milk and whey were higher in milk from buffaloes with a space allocation of $15 \mathrm{~m}^{2}$ per animal than in milk from buffaloes with a space allocation of $10 \mathrm{~m}^{2}$ /animal. Group S15 also had higher milk yield. Buffaloes restricted to $10 \mathrm{~m}^{2}$ per animal have also been reported to have higher blood cortisol levels than buffaloes kept at $10 \mathrm{~m}^{2}$ per animal but allowed access to a wallowing area (Tripaldi et al., 2004). It is possible that buffaloes maintained at $10 \mathrm{~m}^{2}$ per animal experienced increased stress and had elevated blood glucocorticoid levels. The latter can raise plasma glucose levels through increased gluconeogenesis and decreased peripheral tissue glucose uptake. Glucocorticoids also regulate lipolysis and lipogenesis and increase plasma levels of nonesterified fatty acids (Parker and Rainey 2004). The higher content of carnitine, short-chain acylcarnitine, and $\delta$-valerobetaine in buffaloes with a space allocation of $15 \mathrm{~m}^{2}$ per animal could be explained by a shift in the glycogenolysis/ gluconeogenesis ratio to glycogenolysis as a result of increased production of carnitine and its precursors. Carnitine plays a role in the mitochondrial oxidation of long-chain fatty acids through the action of specialized acyltransferases (Fritz, 1959). It can also regulate the mitochondrial acyl-CoA/CoA ratio and buffer the free CoA pool by forming acyl-carnitines and prevent- 
ing acylation of free CoA (Ramsay and Arduini, 1993). Moreover, carnitine can influence energy production from glucose by modifying the available free CoA (Stephens et al., 2007). Carnitine can be used as a carbon source through multistep metabolism to glycine betaine, which is then successively demethylated to glycine that can be used for carbon, nitrogen, and energy depending on the bacterial strain (Wargo and Hogan 2009). In the present study, glycine betaine was higher in the milk and whey of buffaloes maintained at $15 \mathrm{~m}^{2}$ per animal. The greater carnitine and derivatives in milk and whey could be linked to a greater ruminating time in buffaloes kept at $15 \mathrm{~m}^{2}$ per animal Napolitano et al. (2004). The synthesis of the carnitine and its derivatives can be related to the persistence of the feed in the reticulorumen and through the action of specific bacteria (Meadows and Wargo 2015). Indeed, rumen microbiota could influence the carnitine status of ruminants. Together with the microbiota, anaerobic fungi (which synthesize carnitine) are also present (Kaufman and Broquist 1977; Strijbis et al., 2009), but fungi have less effect than bacteria because of their low contribution to rumen microbial mass (Krause et al., 2013).

The higher amounts of betaines (glycine betaine and $\delta$-valerobetaine) and short-chain acylcarnitine in buffaloes maintained at $15 \mathrm{~m}^{2}$ per animal would confer increased health-promoting properties, such as antioxidant and anti-inflammatory activity (D'Onofrio et al., 2019). In addition to improving the hyperglycemicoxidative microenvironment, the in vitro findings from the present study indicated that the milk of buffaloes maintained at $15 \mathrm{~m}^{2}$ per animal also had greater biopotency in suppressing the release of proinflammatory cytokines (TNF- $\alpha$, IL-1 $\beta$, IL-6). It is likely that the bioactive properties of buffalo milk involve the complementary actions of $\delta$-valerobetaine and short-chain acylcarnitine, together with other biomolecules that await discovery. These natural compounds have promising potential for use in combination with hypoglycemic drugs to prevent and control inflammation (Liu et al., 2017; D'Onofrio et al., 2018). Allowing buffaloes to have more space could improve welfare and is associated with higher levels of functional molecules in milk and increased antioxidant activity. This finding has important implications for the use of buffalo milk as a source of biopharmaceuticals in human health and disease.

\section{REFERENCES}

Addeo, F., V. Alloisio, L. Chianese, and V. Alloisio. 2007. Tradition and innovation in the water buffalo dairy products. Ital. J. Anim. Sci. 6(Suppl. 2):51-57.
AOAC (Association of Official Analytical Chemists). 1980. Official Methods of Analysis. 13th ed. AOAC, Washington, DC.

Broom, D. M. 2010. Animal welfare: An aspect of care, sustainability, and food quality required by the public. J. Vet. Med. Educ. 37(Suppl. 1):83-88.

Campanile, G., C. De Filippo, R. Di Palo, W. Taccone, and L. Zicarelli. 1998. Influence of dietary protein on urea levels in blood and milk of buffalo cows. Livest. Prod. Sci. 55(Suppl. 2):135-143.

D'Onofrio, N., A. Balestrieri, G. Neglia, A. Monaco, R. Casale, A. Limone, M. L. Balestrieri, and G. Campanile. 2019. Antioxidant and anti-inflammatory activities of buffalo milk $\delta$-valerobetaine. J. Agric. Food Chem. 67(Suppl. 6):1702-1710.

D'Onofrio, N., L. Servillo, and M. L. Balestrieri. 2018. SIRT1 and SIRT6 signaling pathways in cardiovascular disease protection. Antioxid. Redox Signal. 28(Suppl. 8):711-732.

De Rosa, G., F. Napolitano, F. Grasso, C. Pacelli, and A. Bordi. 2005. On the development of a monitoring scheme of buffalo welfare at farm level. Ital. J. Anim. Sci. 4:115-125.

Fritz, I. B. 1959. Action of carnitine on long chain fatty acid oxidation by liver. Am. J. Physiol. 197:297-304.

INRA. 1988. Alimentation des bovins, ovins et caprins. R. Jarrige, ed. INRA, Paris, France.

Kärkkäinen, O., M. A. Lankinen, M. Vitale, J. Jokkala, J. Leppänen, V. Koistinen, M. Lehtonen, R. Giacco, N. Rosa-Sibakov, V. Micard, A. A. A. Rivellese, U. Schwab, H. Mykkänen, M. Uusitupa, M. Kolehmainen, G. Riccardi, K. Poutanen, S. Auriola, and K. Hanhineva. 2018b. Diets rich in whole grains increase levels of betainized compounds associated with glucose metabolism. Am. J. Clin. Nutr. 108(Suppl. 5):971-979.

Kärkkäinen, O.,, T. Tuomainen, V. Koistinen, M. Tuomainen, J. Leppänen, T. Laitinen, M. Lehtonen, J. Rysä, S. Auriola, A. Poso, P. Tavi, and K. Hanhineva. 2018a. Whole grain intake associated molecule 5 -aminovaleric acid betaine decreases $\beta$-oxidation of fatty acids in mouse cardiomyocytes. Sci. Rep. 8(Suppl. 1):13036.

Kaufman, R. A., and H. P. Broquist. 1977. Biosynthesis of carnitine in Neurospora crassa. J. Biol. Chem. 252:7437-7439.

Krause, D. O., T. G. Nagaraja, A. D. Wright, and T. R. Callaway. 2013. Board-invited review: Rumen microbiology: leading the way in microbial ecology. J. Anim. Sci. 91:331-341.

Liu, T., L. Zhang, D. Joo, and S. C. Sun. 2017. NF-кB signaling in inflammation. Signal Transduct. Target. Ther. 2:17023.

Meadows, J. A., and M. J. Wargo. 2015. Carnitine in bacterial physiology and metabolism. Microbiology 161:1161-1174.

Napolitano, F., G. De Rosa, F. Grasso, and A. Bordi. 2004. Influence of space restriction on welfare of weaned buffalo calves (Bubalus bubalis). Livest. Prod. Sci. 86:117-124.

National Research Council. 2001. Nutrient Requirements of Dairy Cattle. 7th rev. ed. Natl. Acad. Press, Washington, DC.

Neglia, G., B. Gasparrini, R. Di Palo, C. De Rosa, L. Zicarelli, and G. Campanile. 2003. Comparison of pregnancy rates with two estrus synchronization protocols in Italian Mediterranean Buffalo cows. Theriogenology 60:125-133.

Neglia, G., B. Gasparrini, A. Salzano, D. Vecchio, E. De Carlo, R. Cimmino, A. Balestrieri, M. J. D'Occhio, and G. Campanile. 2016. Relationship between the ovarian follicular response at the start of an Ovsynch-TAI program and pregnancy outcome in the Mediterranean river buffalo. Theriogenology 86:2328-2333.

Parker, K. L., and W. E. Rainey. 2004. The adrenal gland. Pages 319-348 in Text Book of Endocrine Physiology. Vol. 14. Oxford University Press, New York, NY.

Ramsay, R. R., and A. Arduini. 1993. The carnitine acyltransferases and their role in modulating acyl-CoA pools. Arch. Biochem. Biophys. 302:307-314.

Rychlik, J. L., R. La Vera, and J. B. Russell. 2002. Amino acid deamination by ruminal Megasphaera elsdenii strains. Curr. Microbiol. $45: 340-345$

Salzano, A., M. S. Spagnuolo, P. Lombardi, D. Vecchio, A. Limone, S. Bolletti Censi, A. Balestrieri, A. Pelagalli, and G. Neglia. 2017. Influences of different space allowance on reproductive performances in buffalo. Anim. Reprod. 14:429-436. 
Servillo, L., N. D’Onofrio, G. Neglia, R. Casale, D. Cautela, M. Marrelli, A. Limone, G. Campanile, and M. L. Balestrieri. 2018a. Carnitine precursors and short-chain acylcarnitines in Water Buffalo milk. J. Agric. Food Chem. 66:8142-8149.

Servillo, L.,, N. D'Onofrio, A. Giovane, R. Casale, D. Cautela, D. Castaldo, F. Iannaccone, G. Neglia, G. Campanile, and M. L. Balestrieri. 2018b. Ruminant meat and milk contain $\delta$-valerobetaine, another precursor of trimethylamine N-oxide (TMAO) like $\gamma$-butyrobetaine. Food Chem. 260:193-199.

Stephens, F. B., D. Constantin-Teodosiu, and P. L. Greenhaff. 2007. New insights concerning the role of carnitine in the regulation of fuel metabolism in skeletal muscle. J. Physiol. 581:431-444.

Strijbis, K., C. W. Van Roermund, G. P. Hardy, J. Van Den Burg, K. Bloem, J. De Haan, N. Van Vlies, R. J. Wanders, F. M. Vaz, and B. Distel. 2009. Identification and characterization of a complete carnitine biosynthesis pathway in Candida albicans. FASEB J. 23:2349-2359.

Tripaldi, C., G. De Rosa, F. Grasso, G. M. Terzano, and F. Napolitano. 2004. Housing system and welfare of buffalo (Bubalus bubalis) cows. Anim. Sci. 78:477-483.

Wagner, J. J., K. S. Lusby, J. W. Oltjen, J. Rakestraw, R. P. Wettemann, and L. E. Walters. 1988. Carcass composition in mature Hereford cows: Estimation and effect on daily metabolizable energy requirement during winter. J. Anim. Sci. 66:603-612.

Wargo, M. J., and D. A. Hogan. 2009. Identification of genes required for Pseudomonas aeruginosa carnitine catabolism. Microbiology 155(Suppl. 7):2411-2419. 